\title{
A Comparative Analysis of Holographic, 3D-Printed, and Computer-Generated Models: Implications for Engineering Technology Students' Spatial Visualization Ability
}

\author{
Petros J. Katsioloudis \& Mildred V. Jones
}

\begin{abstract}
A number of studies indicate that the use of holographic displays can influence spatial visualization ability; however, research provides inconsistent results. Considering this, a quasi-experimental study was conducted to identify the existence of statistically significant effects on sectional view drawing ability due to the impacts of holographic displays. In particular, the study compared the use of three different types of displays: 3D printed model, computer generated model, and holographic model to determine whether a significant difference exists towards sectional view drawing ability, among engineering technology students. According to the results of this study, it is suggested that the impact of the display type provides no statistically significant differences.
\end{abstract}

Keywords: Holographic, spatial visualization, 3-D printed, spatial ability

Generating holographic projections "of medical images and engineering data is a recent topic in visualization" studies (Sheet et al., 2014, p. 103). Complex visualizations require high computer configuration and optical specification, which can be quite difficult and expensive to obtain. However, recent developments in technology have created a growing demand for mature 3D displays and other types of holographic visualization (Gao, Zhang, \& Liu, 2010). According to Luévano, López de Lara, and Castro (2015), "recent research on holography ... [at] the University of Arizona has shown that the development of computer capacities will allow the construction of a threedimensional presence by the year 2018" (p. 340).

In recent years, 3D holographic technology has been used in communication, military training, entertainment, virtual augmented reality, and medical training (Lee, 2013). Even though holographic technology is mainly developed and used outside educational settings, there is certainly educational potential (Lee, 2013). Holographic technology as a learning tool has the potential to promote a student-centered learning environment, placing students in an interactive environment that allows them to construct knowledge based on their individual learning experiences (Lee, 2013). Sudeep (2013) notes the importance of 3D hologram technology, specifically in engineering education. Coursework, such as engineering design and graphics, require various types of 
study, including projection of solids and planes, sectional views of solids, and orthographic projection.

According to Liarokapis et al. (2004), virtual and augmented reality in education " can provide a rewarding learning experience that would be otherwise difficult to obtain" (p. 14), especially for disciplines like engineering education that utilize large and complex data sets (Sudeep, 2013).

However, as with many technological applications in education, 3D holographic technology faces several challenges, such as the quality of 3D renderings, visual fatigue, effectiveness of instructional media, and planning of applications (Lee, 2013). Even though the topic has been under research for 2 decades, no significant achievements had been made until the last 5 years (Sheet et al., 2014). The purpose of the current study is to identify whether the use of holographic technology models versus other traditional types of models can increase or decrease spatial ability performance for engineering technology students.

The following was the primary research question:

Is there an effect on students' (a) spatial visualization ability, as measured by the Mental Cutting Test, and (b) ability to sketch a sectional view drawing, due to the impacts of holographic, 3D-printed, and computergenerated models?

The following hypotheses were analyzed in an attempt to find a solution to the research question:

$\mathrm{H}_{0}$ : There is no effect on students' (a) spatial visualization ability, as measured by the Mental Cutting Test, and (b) ability to sketch a sectional view drawing due to the impacts of holographic, 3D-printed, and computergenerated models.

$\mathrm{H}_{1}$ : There is an identifiable effect on students' (a) spatial visualization ability, as measured by the Mental Cutting Test, and (b) ability to sketch a sectional view drawing due to the impacts holographic, 3D-printed, and computer-generated models.

\section{Spatial Visualization}

\section{Review of Literature}

According to Strong and Smith (2001), "spatial visualization is the ability to manipulate an object in an imaginary 3-D space and create a representation of the object from a new viewpoint" (p. 2). Although visualization in a 3D computer graphics context is not new, the evolution of technology has revealed an increasingly significant focus of visualization as a dominant tool in many different disciplines (Ferri, 2001). In 3D computer graphics, the depth 
perception of an image develops from monocular depth cues (e.g., retinal image size, texture gradients, shading, shadowing, overlapping, motion, linear, and aerial perspective), which "create the illusion of volume and depth on flat image surfaces" (Ferri, 2001, p. 309). Research studies have suggested that as many as 84 career fields require well-developed spatial skills (spatial visualization and rotation abilities, in particular) and play a significant role in success and retention in engineering majors (Maier, 1994; Sorby, Nevin, Mageean, Sheridan, \& Behan, 2014; Smith, 1964).

\section{Augmented Reality vs. Virtual Reality vs. Holograms}

To alleviate any confusion among types of interactive technologies, it is important to distinguish here that there is a difference between augmented and virtual realities and holograms. Using the same hardware technologies, augmented reality (AR) and virtual reality (VR) both share computer-generated virtual scenes, $3 \mathrm{D}$ objects, and interactive components. The difference between these two technologies lies in the way that they are used: "Virtual reality aims to replace the real world while augmented reality respectfully supplements it" (Kesim \& Ozarslan, 2012, p. 298), layering enhancements atop an existing reality (see also, García Domínguez, Martín-Gutiérrez, González, \& Mato Corredeaguas, 2012). According to Kesim and Ozarslan (2012), augmented reality (AR) "brings virtual information or object to any indirect view of user's real-world environment to enhance the user's perception and interaction with the real world" (p. 298). Azuma (1997) defined "AR as any system that": (a) "combines real and virtual," (b) "is interactive in real time," and (c) "is registered in three dimensions" (p. 356). VR is comprised of an environment that has been made up by a computer.

Holography is neither AR nor VR; rather, it is a way of presenting pictures that you can "walk around." It is a technique that allows an image system (camera or eye), directed at the reconstructed beam, to continue seeing an image even when it is no longer present. Holography uses the same technologies as AR and VR; however, it is completely different from AR and VR technology.

\section{Hologram}

Like digital photographs, holograms take light around an object and encrypt it onto a chip. Photographs record the intensity of light; however, holograms capture the "phase" of the light, which gives it a three-dimensional appearance (Khorasaninejad, Ambrosio, Kanhaiya, \& Capasso, 2016). According to Sudeep (2013), "the word, hologram is composed of the Greek terms, 'holos' for 'whole view'; and gram meaning 'written'. A hologram is a three-dimensional record of the positive interference of laser light waves" (p. 63). Mature 3D displays can add value to a broad scope of visualizations used in many fields, such as remotesensing satellites (aerospace engineering), medical imaging devices (biomedical engineering), engineering design, art, advertising, and geological exploration 
(civil and geological; Khan, 2013, Gao et al., 2010). Holograms are advanced enough for commercialized use in many fields today. Holograms are also embedded in current technologies, such as credit card chips, paper currencies, retail scanners, and even biomedical devices (Khorasaninejad et al., 2016; Khan, 2013)

Static analog holograms were popular during the 1980s and 1990s; however, the technology had not yet evolved into a 3D dynamic holographic technology (Khan, 2013). Today, the resurgence of 3D technologies from sources like geographical data, medical scanning, CAD design, simulations, low-cost depth scanners, cinema or TV, and 3D printing have allowed for the development of enriched 3D dynamic holographic content (Khan, 2013).

\section{Holographic Memory}

The human brain may hold memories in a holographic manner, as suggested by Pribram's Holographic Brain Theory (Pribram, 1971, 1991). This theoretical approach to the cognitive processes in the brain suggests that holographic data is distributed rather than localized, such as in plain pictures. According to Berend, Doley, Frenkel, and Hanemann (2016) "each part of the memory (a neuron or a group of neurons) contains some information regarding the entire data" (p. 87). Living systems require not only the intellectual ability to memorize but also the associative property in which the brain establishes connections "between information units (images and concepts) that are not linked during learning," or cognitive processing (Orlov \& Pavlov, 2015, p. 628).

\section{Holographic Technology and Uses in Education}

Typically, 2D media has been used in educational settings because it is convenient, familiar, flexible, portable, and inexpensive. However, 2D static representation does not reflect the natural world, which is three-dimensional (Kesim \& Ozarslan, 2012). Today, virtual 3D environments are more appropriate for learning because the student is submerged in a virtual world representative of the natural world. Known as augmented reality, this "allows the user to see the real world and aim to supplement reality without completely immersing [the] user inside a synthetic environment" (Kesim \& Ozarslan, 2012, p. 298). Although holographic technology is typically developed and implemented outside of the academic arena, the potential in educational settings could be the next step in enhancing the experiences of both the learner and the instructor. As educational paradigms shift from teacher-centered to more student-center models, it is important to consider the tools that enhance the transfer of knowledge (Contero, Naya, Company, \& Saorín, 2006).

According to Lee (2013), "3D holographic technology can find its roots in the illusion known as 'Pepper's ghost' used in Victorian theaters in the 1860s to produce realistic ghosts through a series of optical projections" (p. 34). In the 1960s, the first static 3D holograms were created (Lee, 2013). In 2008, at the 
World Congress on Information Technology, Bill Gates of Microsoft recorded a presentation that was shown as a holographic image in Malaysia. More recently, Cisco Systems and Musion integrated the technology between 3D holographic imaging and real-time virtual communication, allowing Cisco CEO Johan Chambers to appear with presenters who were "beamed" from San Jose to Bangalore, India (Lee, 2013, p. 35).

Although 3D holographic technology could offer enrichment in learning environments, there are also challenges that may hinder implementation in many educational environments. The quality of $3 \mathrm{D}$ renderings is a significant concern in instructional effectiveness in many disciplines, including engineering and medicine. For, example, BioDigital Human is "an online 3D interactive medical visualization program" for understanding anatomy and physiology (Lee, 2013, p. 36). Holographic 3D technology "renderings look 'a little cartoonish"” (Hernandez, 2012, para. 14) compared with other mediums like computer renderings and 3D-printed models.

In addition, visual fatigue has been known to occur following viewings of 3D images (Yano, Ide, Mitsuhashi, \& Thwaitse, 2002). VR-induced sickness, also known as "cybersickness," has been extensively covered in research (Nichols \& Patel, 2002). Educators also need to consider the need for learning activities and student learning outcomes that enhance student-teacher interactions as well as employing student-centered learning approaches for overall effectiveness.

According to Lee (2013), these new technologies also raise concerns regarding cost. Because 3D holographic technology is not fully developed and still needs to be assessed for cost effectiveness, many educational institutions may be uncertain if the cost is worth the investment at this stage.

\section{Methodology}

A quasi-experimental study was used as a means to perform the comparative analysis of rotational view drawing ability during the summer of 2016. The study compared the exposure of engineering technology students to three different kinds of spatial visualization models in order to determine whether a significant difference existed towards sectional view drawing ability. The research protocol was generated and submitted for approval to the College's Human Subjects Review Committee, where it was approved and received exempt status. Data was tested for normality of distribution using the ShapiroWilk test. The data was analyzed by a three-way repeated measures analysis of variance (ANOVA), with motion as the stimulus and the type of stimulus (3Dprinted model, computer-generated model, and a holographic model) as subject factors. Tukey's post hoc analyses were performed to account for multiple comparisons and sample size effect. All data was analyzed using SPSS (Version 25.0). For the analyses, $p<0.01$ was used to establish significant differences. 
The study was conducted in an engineering graphics course, as part of the Engineering Technology program, during the summer semester of 2016. The participants were sophomores and enrolled in the Engineering Technology program. Using a convenience sampling technique, the participants, who were from three different sections of the same course, were assigned into one of three treatment groups. Each group of students was then assigned into a different classroom in which the treatment took place. A common core for all students was the fact that they all previously completed two required mathematics courses (MAT 102: College Algebra and MAT 302: Geometry). As described above, research supports that a positive correlation between mathematics and spatial visualization exists.

The engineering graphics course emphasized hands-on practice using 3D drafting software (Autodesk Inventor) in the computer lab, along with various methods of editing, manipulation, visualization, and presentation of technical drawings. In addition, the course included the basic principles of engineering drawing or hand sketching, dimensions, and tolerance principles. Table 1 shows the participants from the study. Using a convenience sample, there was a near equal distribution of the participants between the three groups. The three groups $\left(n_{1}=44, n_{2}=41\right.$, and $\left.n_{3}=43\right)$, with an overall population of $N=128$, were presented with the same model (dodecahedron) in a 3D-printed format (see Figure 2), a computer-generated model (see Figure 3), and as a hologram (created by using a free iTunes ${ }^{\mathcal{O}}$ application called Holapex ${ }^{\mathcal{O}}$ and projected using a Holapex projection pyramid; see Figures 4 and 5) and were asked to create a sectional view drawing of it. The type of visualization model was the independent variable in this study. Each group member received 60 seconds to observe the model. Upon observation, each student had to create a sectional view of the respective model. To create the sectional view of the model, students had to mentally section the dodecahedron; therefore, this process takes into consideration a learner's visualization ability and level of proficiency. Prior to attending the graphics course in which testing took place, all students had to complete two sections of mathematics (MAT 102: College Algebra and MAT 302: Geometry). Research has shown a positive correlation between mathematics and the spatial visualization ability, and "individual differences in spatial and mathematical abilities are correlated ( .5, e.g. Hegarty \& Kozhevnikov, 1999), and rely on partly overlapping neural networks (Hubbard, Piazza, Pinel, \& Dehaene, 2005)" (Tosto et al., 2014, p. 462). Research suggests these factors can easily be determined through sketching and drawing techniques.

The engineering drawing used in this research was a sectional view of the dodecahedron (see Figure 6). Sectional views are very useful engineering graphics tools, especially for parts that have complex interior geometry because the sections are used to clarify the interior construction of a part that cannot be described by hidden lines in exterior views (Plantenberg, 2013). By taking an 
imaginary cut through the object and removing a portion, the inside features can be seen more clearly. Students had to mentally discard the unwanted portion of the part and draw the remaining portion. The rubric used included the following parts: (a) section view labels, (b) correct hatching style for cut materials, (c) accurate indication of cutting plane, (d) appropriate use of cutting plane lines, and (e) appropriate drawing of omitted hidden features. The maximum score for the drawing was 6 points.

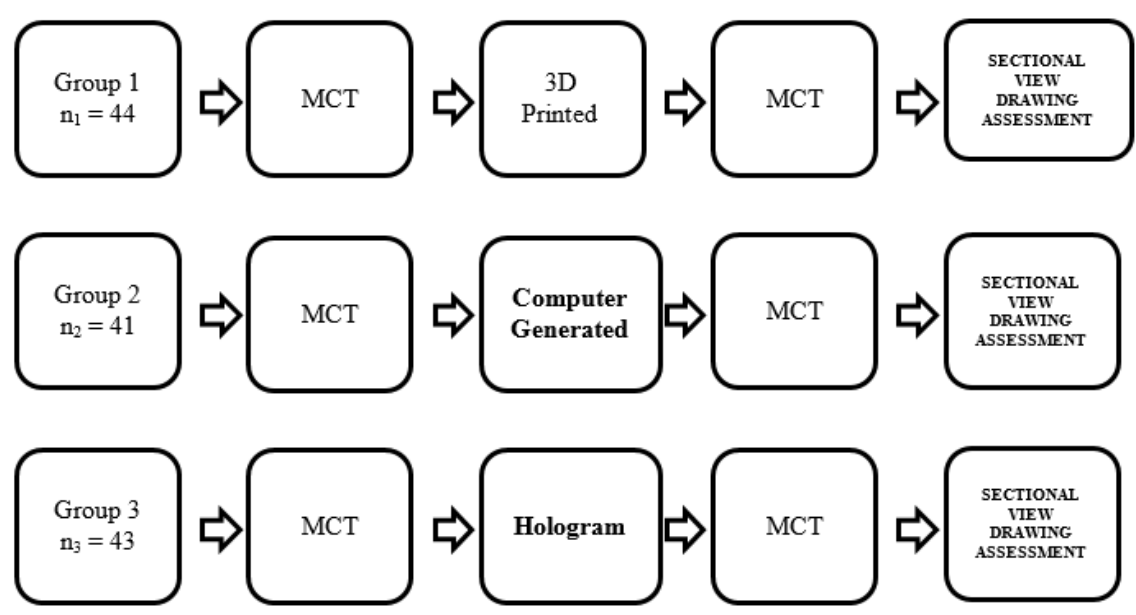

Figure 1. Research design methodology.

In addition, all groups were asked to complete the Mental Cutting Test (MCT; College Entrance Examination Board [CEEB], 1939) instrument 2 days prior to the completion of the sectional view drawing in order to identify the level of visual ability and show equality between the three groups. In this study, the MCT was not used to account for spatial visualization skills. Its only purpose was to establish a near to equal group dynamic based on visual ability, as it relates to mental cutting ability. According to Németh and Hoffman (2006), the MCT (CEEB, 1939) has been widely used in all age groups, making it a good choice for a well-rounded visual ability test. The Standard MCT consists of 25 problems. "The Mental Cutting Test ..., a sub-set of the CEEB Special Aptitude Test in Spatial Relations ... (1939), has also been used by Suzuki et al. . . . [1990] to measure spatial abilities in relation to graphics curricula" (Tsutsumi, 2004, p. 117).

In each problem, subjects are given a perspective drawing of a test solid, which is to be cut with a hypothetical cutting plane. Subjects are then asked to choose one correct cross section from among 5 alternatives. There are 
two categories of problems in the MCT ... [(Suzuki et al., 1990)]. Those of the first category are called 'pattern recognition problems', in which the correct answer is determined by identifying only the pattern of the section. The others are called 'quantity problems' or 'dimension specification problems', in which the correct answer is determined by identifying, not only the correct pattern but also the quantity in the section, e.g., the length of the edges or the angles between the edges. (Tsutsumi, 2004, p. 117)

\section{Data Analysis}

\section{Analysis of MCT Scores}

The first method of data collection involved the completion of the MCT instrument prior to the treatment to show equality of spatial ability as predicted by similar scores between the three groups. Using convenience sampling instead of random assignment the researchers graded the MCT instrument as described in the guidelines by the MCT creators. A standard paper-and-pencil MCT preand post-test was conducted, in which the subjects were instructed to draw intersecting lines on the surface of a test solid with a green pencil before selecting alternatives. The maximum score that could be received on the MCT is 25. The pretest results can be seen in Table $1: n 1=23.726, n 2=22.622$, and $n 3$ $=21.739$. Overall means were higher in the post-test: $n 1=24.563, n 2=23.478$, and $n 3=22.631$. A noticeable difference was seen for the group that completed the treatment using the hologram. Respective means changed from 21.739 to 23.631. It can also be seen that the pretest MCT scores were relatively high. This is probably due to the fact that all students that participated in the study had completed two math courses (algebra and geometry) in previous semesters and were also sophomores in engineering technology. "Spatial ability at age 18 moderately correlates with raw SAT (Scholastic Assessment Test) mathematics scores, and remains a significant predictor of mathematical ability after controlling for general intelligence, processing speed and working memory (Rohde \& Thompson, 2007)" (Tosto et al., 2014, p. 462).

In addition, after treatment was completed, a one-way ANOVA was run to compare mean scores between pre- and post-treatment, as measured through the MCT. There was significant $F(6.181)=.0008, p<0.01$ difference between the three groups' level of spatial visualization ability between pre- and posttreatment, as measured by the MCT instrument (see Table 2). The result suggests that a significant difference occurred between the pre- and posttreatment MCT instrument for one of the groups. Research suggests that even a short intervention could increase someone's spatial ability. 
Table 1

MCT Pre- and Post-Test Descriptive Results

$95 \%$ confidence interval for mean

\begin{tabular}{lccccccc} 
& & Mean & Mean & & & \\
\cline { 6 - 8 } & $n$ & pretest & posttest & $S D$ & $S E$ & Lower bound & Upper bound \\
\hline Group 1 & 44 & 23.726 & 24.563 & 3.042 & 0.976 & 21.783 & 24.533 \\
Group 2 & 41 & 22.622 & 23.478 & 2.631 & 0.756 & 22.983 & 23.431 \\
Group 3 & 43 & 21.739 & 23.631 & 3.871 & 0.865 & 20.789 & 22.953 \\
\hline Total & 128 & 22.695 & 23.173 & 3.181 & 0.865 & 21.851 & 23.639 \\
\hline
\end{tabular}

Table 2

MCT Pre- and Post-Test ANOVA Results

\begin{tabular}{lccccc}
\hline \multicolumn{1}{c}{ Quiz } & $S S$ & $d f$ & $M S$ & $F$ & $p$ \\
\hline $\begin{array}{l}\text { Between } \\
\text { groups }\end{array}$ & 1043.531 & 2 & 62.897 & 6.181 & $* 0.008$ \\
Within groups & 1014.306 & 98 & 10.823 & & \\
\hline Total & 2058.061 & 100 & & & \\
\hline
\end{tabular}

* Denotes statistical significance

The second method of data collection involved the creation of a sectional view drawing (see Figure 2). One researcher graded all sketches using a rubric that included the following parts: (a) section view labels, (b) correct hatching style for cut materials, (c) accurate indication of cutting plane, (d) appropriate use of cutting plane lines, and (e) appropriate drawing of omitted hidden features. The maximum score for the drawing was 6 points. As shown in Table 3 , the group that used the 3D-printed model as part of their treatment $(n=44)$ had a mean observation score of 4.421. The groups that used the computergenerated $(n=41)$ and holographic $(n=43)$ models had higher scores of 5.421 and 5.602, respectively. A one-way ANOVA was run to compare the mean scores for significant differences among the three groups. The result of the ANOVA test, shown in Table 4, was not significant: $F(0.423)=0.532, p<$ 0.01 . The data was dissected further through the use of a post hoc Tukey's honest significant difference (HSD) test. As shown in Table 5, the post hoc analysis shows no statistically significant difference between the computergenerated vs. 3D-printed models ( $p<0.742, d=-.2532$ ), the computer-generated 
vs. holographic models ( $p=.987, d=-.03264)$, and the holographic vs. 3Dprinted models $(p=.542, d=-.3932)$.

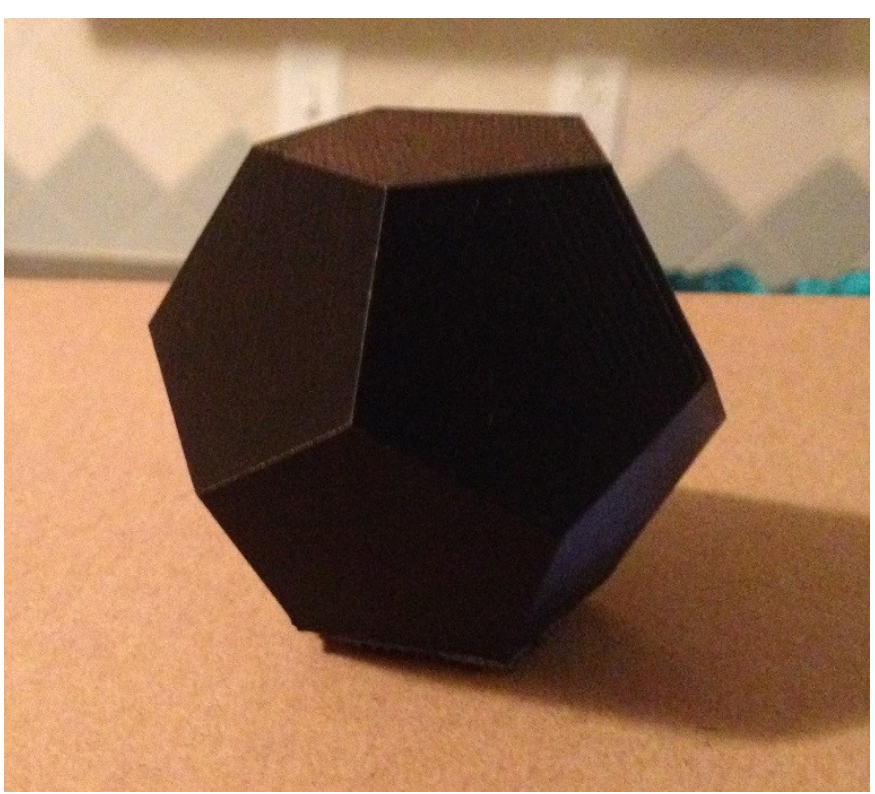

Figure 2. 3D-printed dodecahedron.

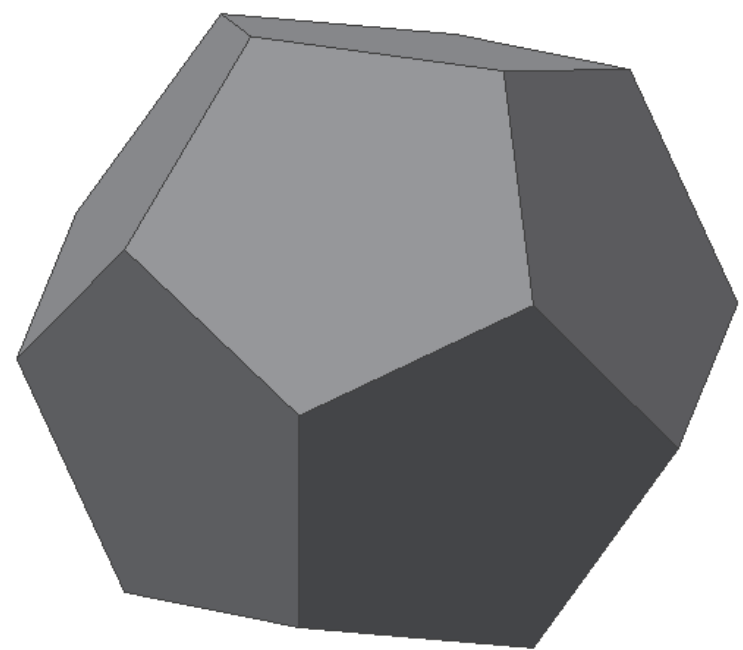

Figure 3. Computer-generated dodecahedron.

$-45-$ 


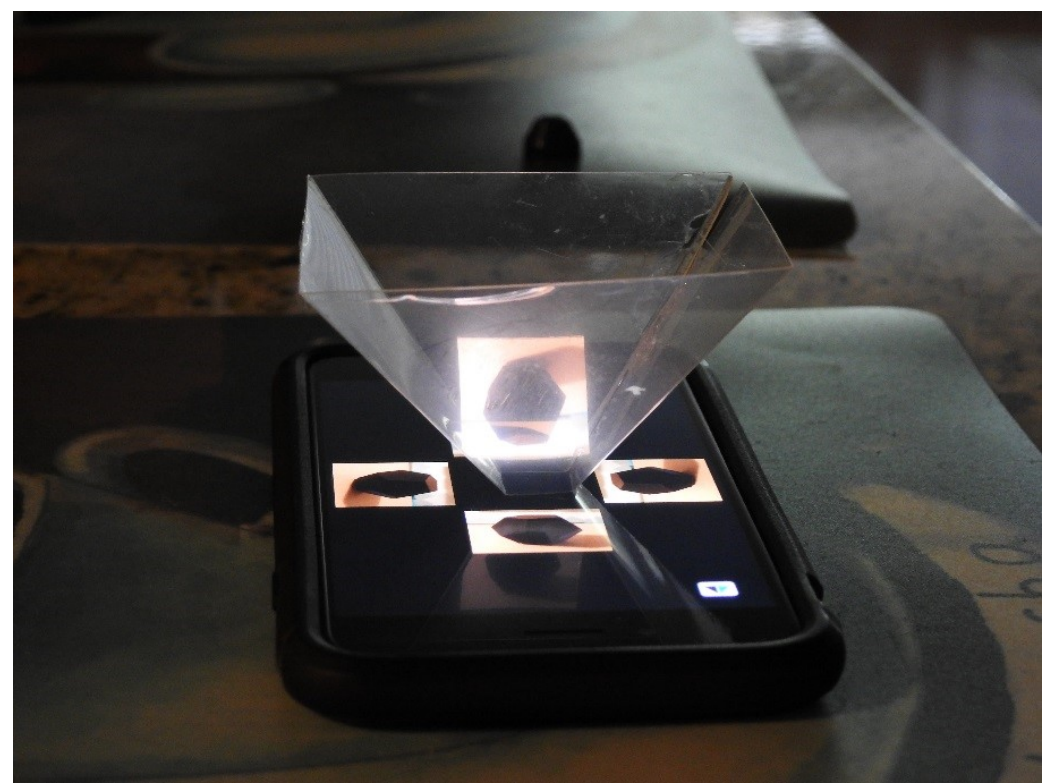

Figure 4. Set up for dodecahedron hologram.

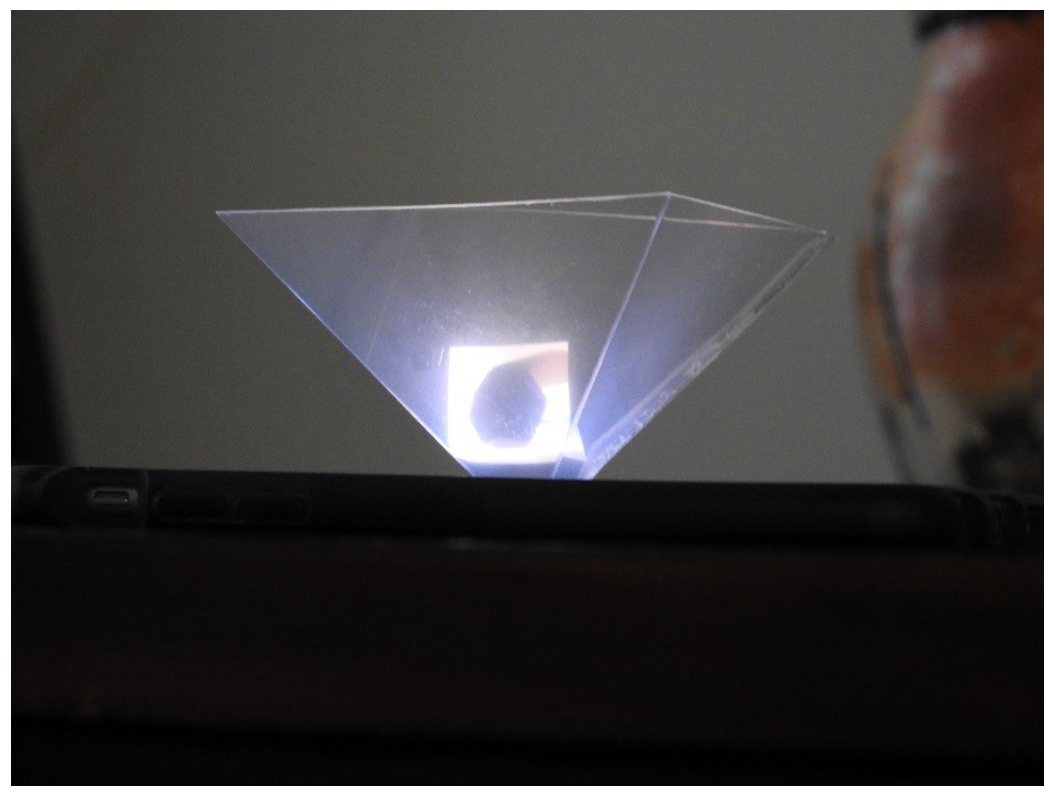

Figure 5. Hologram of dodecahedron. 


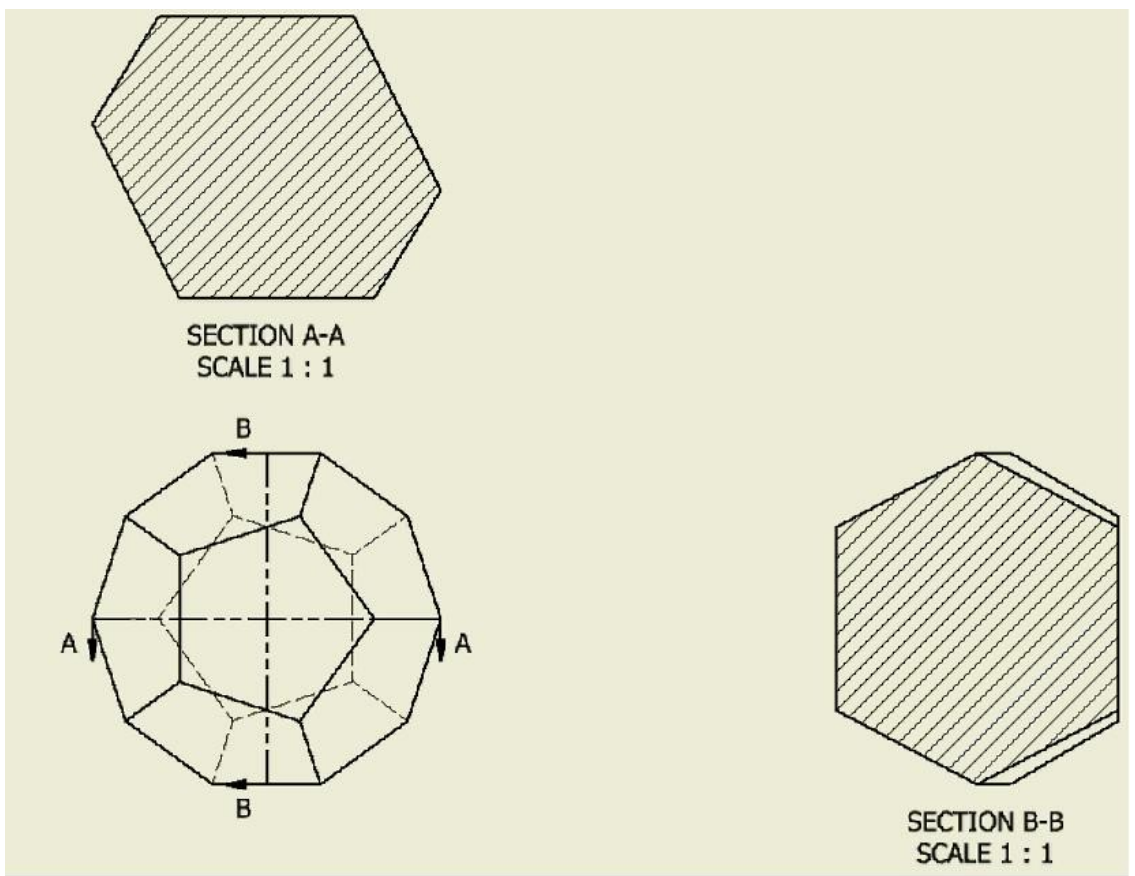

Figure 6. Dodecahedron sectional view.

Table 3

Sectional View Drawing Descriptive Results

$95 \%$ confidence interval for mean

\begin{tabular}{lcccccc}
\cline { 5 - 7 } Groups & & & & & $\begin{array}{l}\text { Lower } \\
\text { bound }\end{array}$ & Upper bound \\
\hline 3D printed & 44 & 4.421 & 1.422 & .394 & 4.422 & 4.341 \\
$\begin{array}{l}\text { Computer } \\
\text { generated }\end{array}$ & 41 & 5.421 & 1.421 & .301 & 4.322 & 5.332 \\
Hologram & 43 & 5.602 & 1.604 & .294 & 4.042 & 5.503 \\
\hline Total & 128 & 5.148 & 1.482 & .329 & 2.262 & 5.058 \\
\hline
\end{tabular}


Table 4

Sectional View Drawing ANOVA Results

\begin{tabular}{lccccc}
\hline \multicolumn{1}{c}{ Quiz } & $S S$ & $d f$ & $M S$ & $F$ & $p$ \\
\hline Between groups & 1.432 & 2 & 0.544 & 0.423 & 0.532 \\
Within groups & 214.432 & 98 & 2.422 & & \\
\hline Total & 215.864 & 100 & & & \\
\hline
\end{tabular}

Table 5

Sectional View Drawing Tukey HSD Results

\begin{tabular}{llccc}
\hline & Visual Models (1 vs. 2 vs. 3) & $\begin{array}{c}\text { Mean Diff. } \\
(1-2)\end{array}$ & $S E$ & $p$ \\
\hline 2 vs & $\begin{array}{l}\text { computer generated vs. 3D } \\
\text { printed }\end{array}$ & -.2532 & .3424 & .742 \\
2 & $\begin{array}{l}\text { computer generated vs. } \\
\text { vo }\end{array}$ & -.0421 & .3264 & .987 \\
3 vs & Hologram & -.3214 & .3932 & .542 \\
1 & & & & \\
\hline
\end{tabular}

\section{Discussion}

This study was done to determine significant positive effects related to sectional view drawing ability. In particular, the study compared the exposure of engineering technology students to three different kinds of treatments (different models for drafting) to determine whether a significant difference exists in sectional view drawing ability due to a specific kind of model.

The null hypothesis - that there is no significant effect on students' (a) spatial visualization ability, as measured by the MCT, and (b) ability to sketch a rotational view drawing, due to the impacts of holographic, 3D-printed, and computer-generate models - was accepted. Although not statistically significant, the students who received treatment using the hologram outperformed their peers who received treatment using 3D-printed and computer-generated models, respectively. In addition, a one-way ANOVA was run to compare mean scores between pre- and post-treatment, as measured through the MCT. There was a significant difference between the three groups' level of spatial visualization ability between pre- and post-treatment, $F(6.181)=.0008, p<0.01$, as measured by the MCT instrument. The results of the one-way ANOVA suggest that after treatment, different groups of students showed a significant difference in their MCT scores. In their study, Liarokapis et al. (2004) found that holographic technology allows students "to understand more effectively through 
interactivity with multimedia content" and "can provide a rewarding learning experience that would be otherwise difficult to obtain" (p. 14). In addition, Eschenbrenner, Nah, and Siau (2008) identified that the benefits of VR in education include, but are not limited, to (a) conducting activities in a risk-free environment, (b) facilitating collaboration and communication, and (c) allowing visualization of abstract or difficult concepts or ideas. In addition, in a study conducted by Ghuloum (2010), 400 teachers from different levels of education in the United Kingdom were surveyed to evaluate the effectiveness of 3D hologram technology as an educational tool. According to the findings, the majority of respondents believed that the technology can enhance learning and constitutes an effective teaching tool.

As with the introduction of many tools in the classroom, implementing holographic technology also includes challenges (Lee, 2013). According to Lee (2013), "the quality of 3D renderings may be one of the most important factors in determining the instructional effectiveness of the technology" (p. 37).

Medical students, for example, could receive additional benefits from using interactive $3 \mathrm{D}$ holographic models versus using $3 \mathrm{D}$ renderings that provide little or limited detail (Lee, 2013). Another issue is the adverse effects, such as visual fatigue (Yano et al., 2002) and cybersickness (Nichols \& Patel, 2002), that have been observed after using 3D and VR technologies.

It is also important to understand that the effectiveness of a new instructional technology is not only strongly correlated with the abilities of the technology itself but also with the users. Kozma (1994) explains that the effectiveness of instructional technology, or media, lies in the capabilities of a particular media or technology in conjunction with the appropriate instructional methods in relation to the learners. For example, in a study conducted by Khooshabeh and Hegarty (2008), it was determined that different types of visual cues found in visual technologies affected the performance of participants with low spatial ability but did not show any significance difference in students who already possessed high spatial abilities, such as those in engineering courses. Learners with high spatial ability are able to use more schematic spatial mental representations, whereas learners with low spatial ability tend to use both visual and spatial information in performing tasks (Khooshabeh \& Hegarty, 2008).

As shown in Table 4, the ANOVA test did not show any significant difference between the three groups, $F(0.423)=0.532, p<0.01$, when measuring the sectional view drawing results. Even though a positive difference in the mean of the hologram treatment was observed, it was not statistically significant enough to promote a stronger positive correlation. This article contributes to understanding the effects of using holograms as an instructional tool to enhance learning. 


\section{Limitations and Future Plans}

In order to have a more thorough understanding of the effects of holograms as it relates to spatial visualization ability for engineering technology students, further research is needed. This study was limited to sophomore engineering technology students that completed two math courses. In addition, a convenience sampling process was used versus random sample assignment. Also, the treatment time was short, it might limit some students' ability to perform better.

Future plans to build on this study include but are not limited to:

- Verifying the results by using additional types of hologram treatments;

- Using a different population, such as technology education, science, or mathematics students;

- Comparing male versus female engineering technology students; and

- Increasing the treatment time.

\section{References}

Autodesk Inventor [Computer software]. San Rafael, CA: Autodesk.

Azuma, R. T. (1997). A survey of augmented reality. Presence: Teleoperators and Virtual Environments, 6(4), 355-385. doi:10.1162/pres.1997.6.4.355

Berend, D., Dolev, S., Frenkel, S., \& Hanemann, A. (2016). Towards holographic "brain" memory based on randomization and Walsh-Hadamard transformation. Neural Networks, 77, 87-94. doi:10.1016/j.neunet.2016.02.001

College Entrance Examination Board. (1939). CEEB Special Aptitude Test in Spatial Relations. New York, NY: Author.

Contero, M., Naya, F., Company, P., \& Saorín, J. L. (2006). Learning support tools for developing spatial abilities in engineering design. International Journal of Engineering Education, 22(3), 470-477. Retrieve from https://www.ijee.ie/articles/Vol22-3/06_ijee1769.pdf

Eschenbrenner, B., Nah, F. F.-H., \& Siau, K. (2008). 3-D virtual worlds in education: Applications, benefits, issues, and opportunities. Journal of Database Management, 19(4), 91-110. doi:10.4018/jdm.2008100106

Ferri, L. C. (2001). Visualization of 3D information with digital holography using laser printers. Computers \& Graphics, 25(2), 309-321. doi:10.1016/S0097-8493(00)00133-3

Gao, Y., Zhang, Z., \& Liu, G. (2010). Three-dimensional display using computer-generated hologram based on virtual optics. Optik, 121(15), 1395-1400. doi:10.1016/j.ijleo.2009.01.025

García Domínguez, M., Martín-Gutiérrez, J., González, C. R., \& Mato Corredeaguas, C. M. (2012). Methodologies and tools to improve spatial ability. Procedia: Social and Behavioral Sciences, 51, 736-744. doi:10.1016/j.sbspro.2012.08.233 
Ghuloum, H. (2010). 3D hologram technology in learning environment. In Proceedings of the Informing Science \& IT Education Conference (pp. 693704). Santa Rosa, CA: Informing Science Institute. doi:10.28945/1283

Hernandez, D. (2012, April 12). A digital revolution for studying human anatomy. Wired. Retrieved from http://www.wired.com/wiredscience/2012/04/biodigital-human

Khan, J. (2013). Biomedical imaging: 3D digital holograms visualize biomedical applications. Laser Focus World, 49(7), 55-59. Retrieved from http://www.laserfocusworld.com/articles/print/volume-49/issue07/features/biomedical-imaging-3d-digital-holograms-visualize-biomedicalapplications.html

Kesim, M., \& Ozarslan, Y. (2012). Augmented reality in education: Current technologies and the potential for education. Procedia: Social and Behavioral Sciences, 47, 297-302. doi:10.1016/j.sbspro.2012.06.654

Khooshabeh, P., \& Hegarty, M. (2008). How visual information affects a spatial task. In Proceedings of the Annual Meeting of the Cognitive Science Society, 30, 2041-2046. Retrieved from http://csjarchive.cogsci.rpi.edu/proceedings/2008/pdfs/p2041.pdf

Khorasaninejad, M., Ambrosio, A., Kanhaiya, P., \& Capasso, F. (2016). Broadband and chiral binary dielectric meta-holograms. Science Advances, 2(5), e1501258. doi:10.1126/sciadv.1501258

Kozma, R. B. (1994). Will media influence learning? Reframing the debate. Educational Technology Research and Development, 42(2), 7-19. doi:10.1007/BF02299087

Lee, H. (2013). 3D holographic technology and its educational potential. TechTrends, 57(4), 34-39. doi:10.1007/s11528-013-0675-8

Liarokapis, F., Mourkoussis, N., White, M., Darcy, J., Sifniotis, M., Petridis, P., ... Lister, P. F. (2004). Web3D and augmented reality to support engineering education. World Transactions on Engineering and Technology Education, 3(1), 11-14. Retrieved from http://www.wiete.com.au/journals/WTE\&TE/Pages/Vol.3,\%20No.1\%20(20 04)/03_Liarokapis29.pdf

Luévano, E., López de Lara, E., \& Castro, J. E. (2015). Use of telepresence and holographic projection mobile device for college degree level. Procedia: Computer Science, 75, 339-347. doi:10.1016/j.procs.2015.12.256

Maier, P. H. (1994). Räeumliches vorstellungsvermögen: Komponenten, geschlechtsspezifische differenzen, relevanz, entwicklung und realisierung in der realschule [Spatial imagination: Components, gender differences, relevance, development and realization in the realschule]. Frankfurt am Main, Germany: Lang.

Németh, B., \& Hoffmann, M. (2006). Gender differences in spatial visualization among engineering students. Annales Mathematicae et Informaticae, 33, 
169-174. Retrieved from http://ami.ektf.hu/uploads/papers/finalpdf/AMI_33_from169to174.pdf

Nichols, S., \& Patel, H. (2002). Health and safety implications of virtual reality: A review of empirical evidence. Applied Ergonomics, 33(3), 251-271. doi:10.1016/S0003-6870(02)00020-0

Orlov, V. V., \& Pavlov, A. V. (2015). On modeling of the biological memory associative properties by the volume superimposed holograms technique. Radiophysics and Quantum Electronics, 57(8-9), 627-634. doi:10.1007/s11141-015-9548-7

Plantenberg, K. (2013). Engineering graphics essentials with AutoCAD ${ }^{\circledR} 2014$ instruction. Mission, KS: SDC Publications.

Pribram, K. H. (1971). Languages of the brain: Experimental paradoxes and principles in neuropsychology. Englewood Cliffs, NJ: Prentice-Hall.

Pribram, K. H. (1991). Brain and perception: Holonomy and structure in figural processing. Hillsdale, NJ: Erlbaum.

Sheet, A., El Sayed, M., Maged, M., Ismail, M., Ali, M., Solouma, N. H., \& Abdel-Mottleb, T. (2014). 3D computer generated medical holograms using spatial light modulators. Journal of Electrical Systems and Information Technology, 1(2), 103-108. doi:10.1016/j.jesit.2014.07.004

Smith, I. M. (1964). Spatial ability: Its educational and social significance. London, England: University of London Press.

Sorby, S., Nevin, E., Mageean, E., Sheridan, S., \& Behan, A. (2014, September). Initial investigations into spatial skills as predictors of success in first-year STEM programmes. Paper presented at the 42nd Annual Conference European Society for Engineering Education, Birmingham, United Kingdom. Retrieved from https://www.sefi.be/wpcontent/uploads/2017/10/0064.pdf

SPSS (Version 25.0) [Computer software]. Armonk, New York: IBM.

Strong, S., \& Smith, R. (2001). Spatial visualization: Fundamentals and trends in engineering graphics. Journal of Industrial Technology, 18(1). Retrieved from

http://c.ymcdn.com/sites/www.atmae.org/resource/resmgr/JIT/strong12200 1.pdf

Sudeep, U. (2013). Use of 3D hologram technology in engineering education. Proceedings of the International Conference on Emerging Trends in Engineering (SICETE), Vol. 4, 62-67.

Tosto, M. G., Hanscombe, K. B., Haworth, C. M. A., Davis, O. S. P., Petrill, S. A., Dale, P. S., ... Kovas, Y. (2014). Why do spatial abilities predict mathematical performance? Developmental Science, 17(3), 462-470. doi: $10.1111 /$ desc. 12138

Tsutsumi, E. (2004). A Mental Cutting Test using drawings of intersections. Journal for Geometry and Graphics, 8(1), 117-126. Retrieved from http://www.heldermann-verlag.de/jgg/jgg08/j8h1tsut.pdf 
Yano, S., Ide, S., Mitsuhashi, T., \& Thwaites, H. (2002). A study of visual fatigue and visual comfort for 3D HDTV/HDTV images. Displays, 23(4), 191-201. doi:10.1016/S0141-9382(02)00038-0

\begin{abstract}
About the Authors
Petros J. Katsioloudis (pkatsiol@odu.edu) is Associate Professor and Chair in the Department of STEM Education and Professional Studies at Old Dominion University.

Mildred V. Jones (mjones@odu.edu) is a Graduate Student in the Department of STEM Education and Professional Studies at Old Dominion University.
\end{abstract}

